\title{
Obesity in Childhood: definition and epidemiology
}

\author{
Zehra Aycan
}

Division of Endocrinology, Dr. Sami Ulus Pediatric Hospital, Altındağ, Ankara, Turkey

Keywords:
obesity, epidemiology,
prevalance
Received: 09 October, 2008
Accepted: 22 October, 2008
Corresponding Author:
Zehra Aycan
Division of Endocrinology,
Dr. Sami Ulus Pediatric
Hospital, Altındağ, Ankara,
Turkey
E-mail:
zehraaycan67@hotmail.com

\section{ABSTRACT}

Obesity is defined as a condition where a pathological excess of body fat is present in an individual. Obesity develops when there is a discrepancy between energy intake and energy output. During its development the original steady-state is disturbed and after a period of positive energy balance, a new steady state at a higher level with an increase in body fat stores is achieved. Since the amount of body fat per se is difficult to determine exactly, for practical use, percentage overweight or the body mass index (BMI) is used to define and to track obesity in childhood. For a given BMI, adiposity varies with age, sex and ethnicity; however, BMI correlates reasonably well with body fat mass and the risk of obesity related diseases.

Childhood obesity is one of the most complex and poorly understood clinical syndromes in pediatrics. Obesity is a common nutritional disorder among children and adolescents in the world. The percentage of overweight children and adolescents has increased by almost 50\% in the past two decades. It has also been observed that about $40 \%$ of overweight children continue to have increased weight during adolescence and $75-80 \%$ of obese adolescents become obese adults. The majority of obesity in adulthood has its origin in childhood, which makes obesity a pediatric concern and the prevention and treatment of obesity a pediatric goal.

Conflict of interest: None declared

Obesity is one of the most complex and poorly understood clinical syndromes affecting children and adults throughout the world. Obesity is an epidemic public health problem in the world. It is only a decade ago that the problem of obesity was seen as a minor issue which concerned only a few endocrinologists intrigued by the manifestations of the condition. Their main concern was to attempt to identify the genetic component of the obesity arising in a few children and adults who put on substantial amounts of weight. Clinical management was also known to be frustrating for both patients and doctors; the major improvements achieved on weight loss were universally recognized but the frequent inability of patients to achieve weight loss led to clinical frustration and the temptation to blame the individual for lack of will power. Now, however, we have a completely different perspective. Obesity is the concern of most, if not all, governments who now readily accept its complexity and major public health impact. Their main concern is now rapidly moving towards prevention and not simply treating the consequences.(1) 


\section{DEFINITIONS}

At birth, the human infant contains about $12 \%$ body fat. During the first years of life, body fat rises rapidly to reach a peak of about $25 \%$ by 6 months of age and then declines to $18 \%$ over the next 10 years. At puberty, there is a significant increase in the percentage of body fat in females and a fall in males. By age 18, males have approximately $15-18 \%$ body fat, females $25-28 \%$. Total body weight, however, rises by only $10-15 \%$ indicating that fat is accounting for a larger part of the rise in body weight and is accompanied by a reduction in lean body mass.(2)

The human body contains essential lipids and also nonessential lipids in the form of triglycerides (triaglycerols) stored in adipose tissue cells known as adipocytes. Obesity is defined as a condition where a pathological excess of body fat is present in an individual. Obesity develops when there is a discrepancy between energy intake and energy output. During its development the original steadystate is disturbed and after a period of positive energy balance, a new steady state at a higher level with an increase in body fat stores is achieved.(3) The level of fatness at which morbidity increases is determined on an actuarial basis. Direct measurements of body fat content, e.g. hydro-densitometry, bioimpedance or DEXA are useful tools in scientific studies; however, body mass index (BMI; weight in kilograms divided by the square of the height in meters) is easy to calculate and is correlated sufficiently with direct measures of fatness. BMI is an imprecise but useful measure of adiposity. $(4,5)$ BMI is therefore frequently used to define obesity clinically. For a given BMI, adiposity varies with age, sex and ethnicity; however, BMI correlates reasonably well with body fat mass and the risk of obesity related diseases. $(6,7)$ A normal BMI in adults is between 18.5 and $<25 \mathrm{~kg} / \mathrm{m}^{2}$. Adults with a BMI $>30$ are classified as obese, whereas those with BMI 25-30 are classified as overweight.(8) This recommendation has been widely accepted and applied. Numerous studies show that BMI is closely associated with body fat and health outcomes in both adults and young people. Nevertheless, there is an ongoing debate on whether the population-specific BMI cut-off points are needed or not. $(9,10)$ The BMI system of classification of obesity is important because it denotes the risk for medical complications of obese patients, which increase at BMI levels above 25 . Individuals with a BMI above 27 have a markedly increased risk for hypertension, hypercholesterolemia, and diabetes mellitus. In contrast, when the BMI is less than 25 , there are no apparent physical effects of obesity on the individual, although there may be social and psychological concerns with body appearance.

In children, defining overweight and obesity is complicated by the fact that weight varies with height as children grow. Characteristically, body adiposity rises sharply during infancy, peaking at about 9 months and decreasing thereafter until about 6 years, when it starts picking up again. This second rise is referred to as adiposity rebound and lasts until adulthood.(11) Since the amount of body fat per se is difficult to determine exactly, in practice, BMI is used to define and to track obesity in childhood. There are several potential errors associated with BMI as an indicator of obesity in children.(12) The increasing height in children from birth until adulthood may cause a difference in the weight for height relationship assumed in current BMI-for-age charts. Gender and age also affect body weight and height. Furthermore, puberty may introduce another change in the weight-for-height relationship. Ethnic origin and social class may also affect both body weight and height. In 1996, a committee of the European Childhood Obesity Group published a proposal to use the relative (age-adjusted) BMI for the definition of childhood obesity.(13) 
As BMI increases from an average age of about 6 or 7 years through puberty to age 17 years, it is necessary to have age- and sexspecific BMI percentiles for each country. The scale of the pediatric obesity epidemic has been underestimated by population secular trends in BMI, even when the most appropriate (national) BMI reference data are used to estimate obesity prevalence.(14, 15) As with the generally accepted $90^{\text {th }}$ and $97^{\text {th }}$ percentiles as cut-off points in the assessment of body weight and height, for BMI the $85^{\text {th }}$ percentile defines overweight and the $95^{\text {th }}$ percentile defines obesity. In 1997, the World Health Organization (WHO) International Obesity Task Force agreed that the pediatric percentiles identified in late adolescence by a BMI of 25 and a BMI of 30 should constitute the cut-off points for the identification of childhood overweight and obesity.

Additional information on the amount of subcutaneous body fat, and perhaps a more precise quantification of obesity, can be obtained by measuring skinfold thickness, especially triceps. Skinfold measurements have been widely used for assessing obesity and are considered good indicators since they directly measure a layer of fat but they are open to numerous sources of both random and systematic errors. Moreover, while skinfold measurements correlate well with total body fat, the size of the correlation is site and sex dependent.(16) One problem with skinfold measurements is that the equations used must be changed for age, gender and ethnic background. Body fat increases with age, even though the sum of the skinfolds remains constant. This means that the fat deposition with age occurs in large part at sites other than subcutaneous ones. Also triceps skinfold, which is typically the site of measurement, is often difficult to grasp and measurement reliability can be poor. It has been observed that there is a strong correlation between BMI and triceps skinfold among age- and gender-matched groups, suggesting that these measures are inter- changeable for use in classifying individuals and in the evaluation of secular trends of obesity and of morbid obesity.(17) However, it should be noted that the clinician measuring skinfolds should be appropriately trained to be accurate.

It has long been known that there are major morphological and metabolic features that differentiate upper from lower body obesity.(18) Body fat distribution is more important than percentage of body fat in predicting morbidity. Adults with a preponderance of abdominal fat as measured by a waist-to-hip ratio (WHR) in excess of 0.8 have a higher frequency of hypertension, hyperinsulinemia, diabetes, and hyperlipidemia than equally obese individuals with predominantly pelvic fat distribution. In addition, a waist circumference (WC) of more than $102 \mathrm{~cm}$ in men and more than 88 $\mathrm{cm}$ in women has been recommended for assessment of obesity related co-morbidities.(19) Also, Wang et al(20) demonstrated that both overall and abdominal adiposity strongly and independently predict risk of Type 2 diabetes and that WC is a better predictor than WHR. In children also there is an increased prevalence of obesity related morbidities with increasing WHR.(21) Thus, the evaluation of body fat distribution is an essential element in the assessment of obesity. Accumulation of body fat in obesity occurs in children at the subcutaneous site, whereas in adolescents, intra-abdominal fat depots also increase. During puberty in girls a gluteo-femoral distribution of body fat develops whereas in boys an abdominal distribution is present. Independent of this sexual dimorphism, high variations in the body fat distribution pattern within one gender can occur. Interestingly, this pattern correlates with associated co-morbidities. ${ }^{3}$ Centrally distributed body fat carries more risk for health than fat located primarily on the hips and thighs. The WC is a practical measure of central adiposity and is a surrogate for more precise measures such as a CT or MRI scan of the abdomen at the L-4-5 position. CT scan, 
or MRI, measures of visceral-to-subcutaneous fat tissue ratio have been shown to be better indices of regional fat distribution than WHR.(22) Recently, the percentiles of WC of children of various racial backgrounds were published. $(23,24)$ When BMI and WC were used to predict the risk of hypertension, dyslipidemia, and the metabolic syndrome, WC was shown to be a better predictor than BMI.(25) In adults, a BMI greater than 28 $\mathrm{kg} / \mathrm{m}^{2}$ is associated with an increased risk of morbidity such as stroke, ischemic heart disease, sleep-apnea syndrome, orthopedic disease or Type 2 diabetes mellitus. A central distribution of body fat is also associated with a higher risk of morbidity and mortality. $(26,27)$ In addition and most importantly, an increased risk of death from cardiovascular disease in adults has been found in subjects whose BMI had been greater than the $75^{\text {th }}$ percentile as adolescents.

Childhood obesity seems to increase the risk of subsequent morbidity whether or not obesity persists in adulthood. $(28,29)$ Age is also an important consideration. A high BMI at a young age implies longer years of excess weight and a higher risk. A rising BMI carries more risk than a stable one. The majority of obesity in adulthood has its origins in childhood, which makes obesity a pediatric concern and the prevention and treatment of obesity a pediatric goal.

\section{PREVALENCE AND EPIDEMIOLOGY}

The prevalence of obesity increased in all age, gender, and ethnic/racial groups during the past 3 decades. Obesity in children is expected to continue to increase in the $21^{\text {st }}$ century, but the consequences of this disease may be more severe as the duration of obesity will be longer.

Obesity is associated with several risk factors for subsequent heart disease and other chronic diseases, including hyperlipidemia, hyperinsulinemia, Type 2 diabetes, hypertension and atherosclerosis. Children who are overweight or obese are more like- ly to become overweight and obese adults. The higher the BMI during childhood, the more likely that obesity will manifest in adulthood. In general, children with a BMI at the $95^{\text {th }}$ percentile or higher have a very high risk for adult obesity.(30) Obesity in adolescence is a primary risk factor for obesity in adulthood. The odds ratio increases from 1.3 for obesity at 1 to 2 years of age to 17.5 for obesity at 15 to 17 years of age.(31) Long-term studies suggest that between 50\% and $75 \%$ of all obese adolescents will become obese adults, and more than onethird of 18-year-olds with BMI higher than the sixtieth percentile will also be overweight as adults.(32)

The National Health and Nutrition Examination Survey (NHANES) program provides national estimates of overweight for adults, adolescents, and children in the United States.

NHANES data demonstrate that the epidemic of childhood obesity is occurring at earlier ages. Based on the 1999-2000 NHANES, $20.6 \%$ of 2 to 5 year old U.S. children were overweight, defined as having a BMI for age at the $85^{\text {th }}$ percentile or higher.(33) It has been shown that $30.4 \%$ of adolescents (12 to 19 years old) have now become obese. The prevalence of obesity, defined as a weight for length at the $95^{\text {th }}$ percentile or higher in children 2 year old or younger, or a BMI higher than the $95^{\text {th }}$ percentile in older children, was $11.4 \%$ among children 0 to 23 months of age, $10.4 \%$ among those 2 to 5 years old, $15.3 \%$ among 6 to 11 year olds, and 15.5\% among adolescents. The prevalence of obesity was not significantly different in the two sexes. It was slightly higher in 2 to 5 year old girls (11.0\% vs. 9.9\%), 6 to 11 year old boys (16.0\% vs $14.5 \%)$, and similar (15.5\%) in adolescents. In all age ranges, the prevalence has increased in comparison to the previous report of NHANES III (1998-1994). The most striking change, from $11 \%$ to $15 \%$, occurred among 6 to 19 year olds.

In the United States, the NHANES document shows a steady increase from the late 
1970s to 2004 in the prevalence of overweight (having a body mass index -BMIabove the age and sex-specific $95^{\text {th }}$ percentile of the US growth reference) and at risk of overweight (a BMI between the $85^{\text {th }}$ and $95^{\text {th }}$ percentile) among children and adolescents, ages 2 to 18 years. The percentage of overweight youth increased sharply from 1999 to 2004 , so that by $2004,17.1 \%$ of American children and adolescents were overweight, and an additional $16.5 \%$ were at risk of overweight. Nearly $14 \%$ of $2-5$ year old children and 19\% of 6-11 year old children were overweight.(34) In addition to increasing BMI, there have also been trends toward higher WC indicative of abdominal obesity, which is of concern because of its association with increased risk of Type 2 diabetes and cardiovascular diseases. Li et al.(35) reported a 65\% increase in WC among boys and a 69\% increase among girls from the 1988-1994 to 1999-2004 NHANES surveys.

Marked race/ethnic differences can be seen in weight status trends.(34) The highest overall overweight prevalence was observed in African American and Mexican American youth. Comparing time trends within race/ethnic groups, African American 6 to 17 year old youth had much larger increases in mean BMI and overweight prevalence over the last 30 years compared to white children. In contrast, despite a higher overall prevalence in minority children, the largest increases in mean BMI among 2 to 5 year olds were observed in white children.(36) Globally, rates of child obesity are increasing dramatically as well. In many countries, including the US, the UK, Australia, China and Brazil, child overweight rates are increasing at a faster rate than adult obesity.(37) In the UK child obesity rates doubled or tripled from 1974 to2002.(38) Trends in overweight during infancy have not been documented from recent national survey data: Based on NHANES III, Ogden et al.(39) reported that $10.3 \%$ of infants ( $<1$ year of age) had a weight for length Z-score above the $95^{\text {th }}$ percentile, with rates higher in girls than boys $(11.0 \%$ versus 9.6\%) and in particular, in Mexican American (15.5\%) and black girls (15\%).

Between 3000 and 14,000 children and adolescents aged 6-17 years were examined in each of the five cross-sectional studies: the National Health Examination Survey, cycle II (NHES II 1963-1965, ages 6-11 years) and cycle III (NHES III 1966-1970, ages 1217 years) and the first, second and third NHANESs (NHANES I 1971-1974; NHANES II 1976-1980; NHANES III 1988-1994).(40, 41, 42, 43) The surveys were all based on nationally representative samples and, since the same standardized measurements were used throughout, they permit a unique and comprehensive examination of the changes in obesity status of the pediatric population in the United States. Over the 30 year period encompassed by these surveys, the prevalence of obesity in the childhood population has increased dramatically, particularly from the mid 1970s onwards. Between 1963 and 1994 , the age adjusted prevalence of obesity in 6-17 year olds has increased from approximately $4 \%$ to $11 \%$. A further $14 \%$ are currently at risk of becoming overweight (BMI between the $85^{\text {th }}$ and $95^{\text {th }}$ percentile). Furthermore, the rates are continuing to increase. Even within the 6 year time span of the NHANES III study, the prevalence of overweight has increased by approximately 2 to 6 percentage points (absolute) in most age, sex and racial ethnic groups.(44)

These prevalence data broadly correspond with other North American studies. Longitudinal data from the Bogalusa Health Study show that the prevalence of overweight among 5 to 24 year olds from a biracial community $(n=11,564)$ increased approximately two-fold between 1973 and 1994.(45) Moreover, the yearly increases in relative weight and obesity during the latter part of the study period (1983-1994) were approximately $50 \%$ greater than those between 1973 and 1982. Similar trends in obesity have also been observed in the baseline data from the National Heart, Lung, and Blood Institute Growth and Health 
Study.(46) Not only has the overall prevalence of obesity in North American children and adolescents increased, but examination of the shifts over time in the BMI distribution show that the distribution has skewed to the right. Thus, the fattest children are getting fatter which, in turn, increases the probability that overweight in childhood will track into adulthood.(47) Undoubtedly, given these circumstances, the high prevalence of obesity is set to continue and, furthermore, will probably increase in the future.

The global epidemic of obesity has affected English children substantially. Using International Obesity Taskforce definitions for overweight and obesity,(48) among 5-10 year olds between 1974 and $2002 / 2003$ the prevalence of overweight rose from $11.3 \%$ to $22.6 \%$ in boys and $9.6 \%$ to $23.7 \%$ in girls, and obesity rose from $1.8 \%$ to $6.0 \%$ in boys and $1.3 \%$ to $6.6 \%$ in girls.(49) There was a two-to five fold increase in the prevalence of overweight and obesity in English children over the three decades up to the early 2000s, with the most rapid rise occurring in the 1990s. $(50,51)$ In Scotland from 1974 to 1994, the proportion of overweight in 4-11 year olds increased from $5.4 \%$ to $10.0 \%$ in boys and $8.8 \%$ to $15.8 \%$ in girls, and the proportion of obese increased from $1.7 \%$ to $2.1 \%$ in boys and $1.9 \%$ to $3.2 \%$ in girls. (52)

In the European Union (EU), there are around 22 million overweight children (5 million of these are obese). Assuming a consistent rise in prevalence of overweight and obesity, it is projected, that by 201026 million will be overweight (rising by about 1.3 million per year) and, of these children, 6.4 million will be obese (rising by 350,000 per year).(53)

Rising BMI has been reported in children as young as 3 years old. In England between 1988 and 1998, the proportion of 3 year olds above the $85^{\text {th }}$ centile of the 1990 British Growth Reference(54) rose from $14.7 \%$ to $23.6 \%$ and those above the $95^{\text {th }}$ centile rose from $5.4 \%$ to 9.2\%.(51) Rising BMI continued in Scottish preschool children between 1995 and 2001.(55)

\section{Differences in prevalence associated with socio-economic status and ethnicity}

The prevalence of childhood obesity is increasing, not only in developed countries, but also in some developing countries. In the developed world at present pediatric obesity is inversely associated with socio-economic status (SES), the more disadvantaged groups being at greatest risk. $(56,57)$ In contrast, in most developing countries at present the wealthier children are at greatest risk of obesity. $(56,58,59)$ Increasing economic development tends to be associated with increases in prevalence of pediatric obesity in developing countries. $(56,59)$ Some countries have shown declines in prevalence of pediatric obesity in recent years, and this has been attributed to economic crisis. (56)

The magnitude of SES differences in obesity risk is worth considering. In the past these differences have been misinterpreted to mean that children from wealthy families in the developed world are at low risk or have been unaffected by the epidemic although this was not the case. For example, in Scottish 3 year olds in 1998/1999 the adjusted odds ratio for obesity $\left(\right.$ BMI $>98^{\text {th }}$ percentile, UK 1990 reference data) for children in the most socio-economically deprived group relative to the least deprived group was only 1.43 (95\% CI 1.16-1.17), and prevalence of obesity was significantly higher than UK 1990 reference data in both the most affluent (3.7\%) and most deprived (4.7\%) groups.(60) Differences in obesity prevalence with SES may therefore be detectable only in relatively large samples. In England and Scotland, two large studies $(60,61)$ observed significant SES differences, smaller studies generally have not. Racial or ethnic differences in obesity risk may also be explained in part by economic factors. However, there is evidence from the USA that racial/ethnic differences in obesity risk are not merely the result of differences in income and education. Rather, there appears to be a cultural component in 
lifestyle which is responsible for the obesity risk in some minority groups.(62)

In England in 1996, obesity was commoner among those with less education, and in women of a lower occupational status.(63) Birth cohort studies suggest that lower SES in childhood is a associated with higher BMI in adulthood.(64) Although obesity varies with SES in children, the gap may have narrowed in the 1990s, at least in some areas.(65) In developing countries, higher social status is associated with obesity but the burden of obesity shifts towards the lower socioeconomic groups as the country's income rises, and affects women at the early stages of economic development.(66) Education may be 'protective' against obesity in high-income countries but is a risk for obesity in low-income countries, depending on the stage of economic development.

The reported prevalence of overweight and obesity in European countries ranges between 16\% in the Czech Republic and 33\% in Greece.(67) Overweight and obesity are also important epidemic health problems in developing countries. The WHO MONICA Project (monitoring trends and determinants in cardiovascular disease) has shown that over 30\% of the population in the Middle East is overweight.(68) Sibai et al.(69) reported that the prevalence of overweight and obese Lebanese children was $22.5 \%$ and $7.5 \%$ respectively. ElHazmi and Warsy(70) reported that the prevalence of overweight and obese Saudi boys and girls in 2002 was $10.7 \%$ and $6.0 \%$ vs. $12.7 \%$ and $6.74 \%$ respectively. In Turkey, few representative nationwide studies on the prevalence of overweight and obese children are available. Publications in English are scarce; moreover, all of these have used data only from selected areas in Turkey and small samples. The reported prevalence of obesity was $0.9 \%$ in boys and 3.8\% in girls in Elazı̆̆ city centre, eastern Turkey.(71) In contrast to these prevalence rates, the reported prevalence of obesity in boys and girls was $11.2 \%$ and 9.4\%, respectively, in İstanbul, in western Turkey.(72) Şimşek et al(73) reported that prevalence of overweight and obesity in children was 10.3\% and $6.1 \%$ respectively, in the west Black Sea region. Although the overall obesity prevalence in Turkey is relatively low compared with children from other European countries, the children in an urban setting and higher socioeconomic group had a higher prevalence of overweight and obesity. Westernization of the behavior patterns of children and living in an urban setting in developing countries are main risk factors for obesity. These marked differences in the prevalence rates for the different population groups in different countries may be due to environmental, genetic and socioeconomic factors. It is well known that the prevalence of obesity and age-dependent BMI are higher in children from developed countries than developing countries. In developed countries, the urban poor are more susceptible to obesity, presumably because of poor dietary practices and limited opportunity for physical activity. In contrast, obesity is more frequent in upper socioeconomic classes in developing countries, probably because of transition to a more Western lifestyle with a more energy-dense diet containing higher level of fat and sugar, which tend to be more palatable at a lower cost.

In conclusion, the global epidemic obesity has affected children worldwide. Obesity is now the most common disorder of childhood in the developed world and its prevalence is still increasing. Pediatric obesity causes ill health in both childhood and adulthood, which is important from a public health perspective and the governments should promote healthy nutrition and physical activity in children.

\section{REFERENCES}

1. James WPT. The epidemiology of obesity: the size of the problem. Journal of Internal Medicine 2008; 263;336-352. [Abstract / Full Text / PDF] 
2. Bray GA, Bellanger T. Epidemiology, trends, and morbidities of obesity and the metabolic syndrome. Endocrine 2006; 29:109-117. [PDF]

3. Wabitsch M. Overweight and obesity in Europen children: definition and diagnostic procedures, risk factors and consequences for later health outcome. Eur J Pediatr 2000;159(Suppl.1): 8- 13. [PDF]

4. Villareal DT, Apovian CM, Kushner RF, Klein S. American society for Nutrition;NAASO, The obesity society. Obesity in older adults: technical review and position statement of the American Society for Nutrition and NAASO, The Obesity Society. Obes Res 2005;13:1849-1863. [Abstract]

5. WHO Expert Consultation. Appropriate body-mass index for Asian populations and its implications for policy and intervention strategies. Lancet 2004; 363;157-163. [PDF]

6. Gallagher D, Visser M, Sepúlveda D, Pierson RN, Harris T, Heymsfield SB. How useful is body mass index for comparison of body fatness across age, sex, and ethnic groups? Am J Epidemiol 1996;143:228-239. [Abstract / PDF]

7. Haslam DW, James WP. Obesity. Lancet 2005;366:1197-1209. [PDF]

8. World Health Organisation. Obesity: Preventing and Managing the Global Epidemic. World Health Organisation. Geneva. 2000.

9. Misra A. Revisions of cutoffs of body mass index to define overweight and obesity are needed for the Asian-ethnic groups. Int J Obes Relat Metab Disord 2003;27:1294-1296. [Full Text]

10. Stevens J. Ethnic-specific revision of body mass index cutoffs to define overweight and obesity in Asians are not warranted. Int J Obes Relat Metab Disord 2003;27:1297-1299. [Abstract]

11. Rolland-Cachera MF, Deheeger M, Bellisle F, Sempe M, Guilloud-Bataille M, Patois E. Adiposity rebound in children: a simple indicator for predicting obesity. Am J Clin Nutr 1984;39:129-135. [Abstract]

12. Bellizzi MC, Dietz WH. Workshop on childhood obesity: summary of the discussion. Am J Clin Nutr 1999;70:173S-175S. [Abstract / Full Text]

13. Poskitt EME and the European Chilhood Obesity Group. Committee report. Defining childhood obesity: the relative body mass index (BMI). Acta Paediatr 1995;84:961-963. [Abstract / PDF]

14. Reilly JJ. Descriptive epidemiology and health consequences of childhood obesity. Best Prac Res Clin Endocrinol Metab 2005;19:327-341. [Abstract]

15. Bundak R, Furman A, Gunoz H, Darendeliler F,Bas F, Neyzi O. Body mass index references for Turkish children. Acta Paediatr 2006;95:194-198. [Abstract]

16. Rolland-Cachera MF, Bellisle F, Sempe M. The prediction in boys and girls of the weight/height index of various skin fold measurements in adults: a two-decade follow-up study. Int J Obes 1989; 13:305-311. [Abstract]

17. Must A, Dallal GE, Dietz WH. Reference data for obesity: $85^{\text {th }}$ and $95^{\text {th }}$ percentiles of body mass index(wt/ht2) and triceps skin fold thickness. Am J Clin Nutr 1991;53:839-846. [Abstract / PDF]

18. Evans DJ, Hoffmann RG, Kalkhoff RK, Kissebah AH. Relationship body fat topography to insulin sensitivity and metabolic profiles in premenopausal woman. Metabolism 1984;33:68-75. [Abstract]

19. Okosun IS, Choi S, Dent MM, Jobin T, Dever GE. Abdominal obesity defined as a larger than expected waist girth is associated with racial/ethnic differences in risk of hypertension. J Hum Hypertens 2001;15:307-312. [Abstract / PDF]

20. Wang Y, Rimm EB, Stampfer MJ, Willett WC, Hu FB. Comparison of abdominal adiposity and overall obesity in predicting risk of type 2 diabetes among men. Am J Clin Nutr 2005;81:555-563. [Abstract / Full Text]

21. Hirschler V, Aranda C, Calcagno MdeL, Maccalini G, Jadzinsky M. Can waist circumference identify children with the metabolic syndrome? Arch Pediatr Adolesc Med 2005;159:740-744. [Abstract / Full Text / PDF]

22. Garn SM, Sullivan TV, Hawthorne VM. Fatness and obesity of the parents of obese individuals. Am J Clin Nutr 1989;50:1308-1313. [Abstract / PDF]

23. Fernández JR, Redden DT, Pietrobelli A, Allison DB. Waist circumference percentiles in nationally representative samples of African-American, Europen- American, and Mexican-American children and adolescents. J Pediatr 2004; 145:439-444. [Abstract / Full Text / PDF]

24. Hatipoglu N, Ozturk A, Mazicioglu MM, Kurtoglu S, Seyhan S, Lokoglu F. Waist circumference percentiles for 7-to 17-year-old Turkish children and adolescents. Eur J Pediatr 2008;167:383-389. [PDF]

25. Janssen I, Katzmarzyk PT, Ross R. Waist circumference and not body mass index explains obesityrelated health risk. Am J Clin Nutr 2004;79:379-384. [Abstract / Full Text / PDF] 
26. Calle EE, Thun MJ, Petreli JM, Rodriguez C, Heath CW. Body-mass index and mortality in a prospective cohort of U.S. adults. New Eng/ J Med 1999;341:1097-1105. [Abstract / Full Text / PDF]

27. Rosenbaum M, Leibel R, Hirsch J. Obesity. New Engl J Med 1997;337:396-407. [Abstract]

28. Barker DJ. In utero programming of cardiovascular disease. Theriogenology 2000; 53:555-574. [Abstract]

29. Bray GA. Overweight is risking fate. J Clin Endocrinol Metab 1999;84;10-12. [Full Text / PDF]

30. Dietz WH. Health consequences of obesity in youth: childhood predictors of adult disease. Pediatrics 1998;101:518-525. [Abstract / Full Text / PDF]

31. Styne DM. Childhood and adolescent obesity. prevalence significance. Pediatr Clin North Am 2001;48:823-854. [Abstract / Full Text / PDF]

32. Guo SS, Wu W, Chumlea WC, Roche AF. Predicting overweight and obesity in adulthood from body mass index values in childhood and adolescence. Am J Clin Nutr 2002;76:653-658. [Abstract / PDF]

33. Ogden $\mathrm{CL}$, Flegal KM, Carroll MD, Johnson CL. Prevalence and trends in overweight among US children and adolescents, 1999-2000. JAMA 2002;288:1728-1732. [Abstract / Full Text / PDF]

34. Ogden CL, Carroll MD, Curtin LR, McDowell MA, Tabak CJ, Flegal KM. Prevalence of overweight and obesity in the United States, 1999-2004. JAMA 2006;295:1549-1555. [Abstract / Full Text / PDF]

35. Li C, Ford ES, Mokdad AH, Cook S. Recent trends in waist cicumference and waist-height ratio among US children and adolescents. Pediatrics 2006;118:e1390-e1398. [Abstract / Full Text / PDF]

36. Freedman DS, Khan LK, Serdula MK, Ogden CL, Dietz WH. Racial and ethnic differences in secular trends for childhood BMI, weight, and height. Obesity (Silver Spring) 2006;14:301-308. [Abstract / Full Text / PDF]

37. Popkin BM, Conde W, Hou N, Monteiro C. Is there a lag globally in overweght trends for children compared with adults? Obesity (Silver Spring) 2006;14:1846-1853. [Abstract / Full Text / PDF]

38. Stamatakis E, Primatesta P, Chinn S, Rona R, Falascheti E. Overweight and obesity trends from 1974 to 2003 in English children: what is thr role of socioeconomic factors? Arch Dis Child 2005;90:9991004. [Abstract / PDF]

39. Ogden CL, Troiano RP, Briefel RR, Kuczmarski RJ, Flegal KM, Johnson CL. Prevalence of overweight among preschool children in the United States 1971 through 1994. Pediatrics 1997;99:E1 [Abstract / Full Text / PDF]

40. National Center for Health Statistics(1967) Plan, operation and response results of a program of children's examinations. Vital Health Stat 11967 Oct;(5):1-56.

41. National Center for Health Statistics (1969) Plan, operation of a Health Examination Survey of US youths 12-17 years of age. Vital Health Stat 1:8.

42. National Center for Health Statistics (1973) Plan and operation of a Health and Nutrition Examination Survey, United States 1971-1973. Vital Health Stat 1: 1973 Feb;(10a):1-46.

43. National Center for Health Statistics (1994) Plan and operation of the Third National Health and Nutrition Examination Survey 1988-1994. Vital Health Stat 1:32.

44. Troiano RP, Flegal KM. Overweight children and adolescents: description, and demographics. Pediatrics 1998;101:497-504. [Abstract / Full Text / PDF]

45. Freedman DS, Srinivasan SR, Valdez RA, Williamson DF, Berenson GS. Secular increases in relative weight and adiposity among children over two decades; the Bogalusa Healt Study. Pediatrics 1997;99:420-426. [Abstract / Full Text / PDF]

46. Campaigne BN, Morrison JA,Schumann BC, Falkner F, Lakatos E, Sprecher D, Schreiber GB. Indexes of obesity and comparisons with previous national survey data in 9- and 10-year-old black and white girls: the National Heart, Lung, and Blood Institute Growth and Health Study. J Pediatr 1994;124:675-680. [Abstract / PDF]

47. Whitaker RC, Wright JA, Pepe MS, Seidel KD, Dietz WH. Predicting obesity in young adulthood from childhood and parental obesity. N Eng J Med 1997;337:869-873. [Abstract / Full Text / PDF]

48. Cole TJ,Bellizzi MC, Flegal KM,Dietz WH. Establishing a Standard definition for child overweight and obesity wordwide: international survey. BMJ 2000;320:1240-1243. [Abstract / Full Text / PDF]

49. Stamatakis E, Primatesta P, Chinn S, Rona R, Falascheti E. Overweight and obesity trends from 1974 to 2003 in English children: what is the role of socioeconomic factors? Arc Dis Child 2005; 90:9991004. [Abstract / Full Text] 
50. Lobstein TJ, James WP, Cole TJ. Increasing levels of excess weight among children in England. Int J Obes RELAT Metab Disord 2003;27:1136-1138. [Abstract]

51. Bundred P, Kitchiner D, Buchan I. Prevalence of overweight and obese children between 1989 and 1998: population based series of cross sectional studies. BMJ 2001;322:326-328. [Abstract / Full Text / PDF]

52. Chinn S, Rona RJ. Prevalence and trends in overweight and obesity in three cross sectional studies of British Children, 1974-94. BMJ 2001;322:24-26. [Abstract / Full Text / PDF]

53. Jakson-Leach R, Lobstein T. Estimated burden of paediatric obesity and co-morbidities in Europe. Part 1. The increase in prevalence of child obesity in Europe is itself increasing. Int $J$ Pediatr Obes 2006;1:26-32. [Abstract]

54. Cole TJ, Freeman JV, Preece MA. British 1990 growth reference centiles for weight, height, body mass index and head circumference fitted by maximum penalized likelihood. Stat Med 1998;17:407-429. [Abstract / PDF]

55. Chinn S, Rona RJ. Prevalence and trends in overweight and obesity in three cross sectional studies of British Children, 1974-94. BMJ 2001;322:24-26. [Abstract / Full Text / PDF]

56. Losstein T, Baur L, Uauy R; IASO International obesity TaskFarce. Obesity in children and young people: a crisis in public health. Obes Rev 2004; 5(Suppl 1):4-104. [Abstract]

57. Armstrong J, Reilly JJ. The prevalence of obesity and undernutrition in Scottish children: growth monitoring within the Child Health Surveillance Programme. Scott Med J 2003;48:32-37. [Abstract]

58. de Onis $M$, Blössner $M$. Prevalence and trends of overweight among preschool children in developing countries. Am J Clin Nut 2000;72:1032-1039. [Abstract / Full Text]

59. Martorell R, Kettel Khan L, Hughes ML, Grummer-Strawn LM. Overweight and obesity in pre-school children from developing countries. Int J Obes Metab Disord 2000;24:959-967. [Abstract / PDF]

60. Armstrong J, Drosty AR, Reilly JJ, Emmett PM; Child Health Information Team. Co-existence of social inequalities in under-nutrition and obesity in pre-school children: population based cross-sectional study. Archives of Disease in Childhood 2003;88:671-675. [Abstract / Full Text]

61. Kinra SJ, Nelder RP, Lewendon GJ. Deprivation and childhood obesity: a cross sectional study of 20,973 children in Plymouth, United Kingdom. J Epidemiol Community Health 2000;54:456-460. [Abstract / Full Text]

62. Gordon-Larsen P, Adair LS, Popkin BM. The relationship of ethnicity, socioeconomic factors, and overweight in US adolescents. Obes Res 2003;11:121-129. [Abstract / Full Text / PDF]

63. Wardle J, Waller J, Jarvis MJ. Sex differences in the association of socioeconomic status with obesity. Am J Public Health 2002;92: 1299-1304. [Abstract / Full Text / PDF]

64. Parsons TJ, Power C, Logan S, Summerbell CD. Childhood predictors of adult obesity: a systematic review. Int J Obes Relat Metab Disord 1999(Suppl 8);23:S1-S107. [Abstract]

65. Buchan IE, Bundred P, Kitchiner DJ, Canoy D, Cole TJ. The spread of child obesity, after birth, through the 1990s in England (Abstract). Obes Rev 2006;7:39-98.

66. Monteiro CA, Moura EC, Conde WL, Popkin BM. Socioeconomic status and obesity in adult populations of developing countries: a review. Bull World Health Organ 2004;82:940-946. [Abstract / Full Text / PDF]

67. Padez C, Fernandes T, Mourão I, Moreria P, Rosado V. Prevalence of overweight and obesity in 7-9-yearold Portuguese children: trends in body mass index from 1970-2002. Am J Hum Biol 2004;16:670-678.

68. Gurney M, Gorstein J. The global prevalence of obesity-an initial overview of available data. World Health Stat Q 1988;41:251-254. [Abstract]

69. Sibai AM, Hwalla N, Adra N, Rahal B. Prevalence and covariates of obesity in Lebanon:findings from the first epidemiological study. Obes Res 2003;11: 1353-1361. [Abstract / Full Text / PDF]

70. El-Hazmi MAF,Warsy AS. A comparative study of overweight and obesity in children in different provinces of Saudi Arabia. J Trop Pediatr 2002;48:172-177. [Abstract / PDF]

71. Aygun D, Akarsu S, Yenioglu H, Kocabay K, Guvenc H. Elazıg il merkezinde adolesan çağda obezite prevalansı(in Turkish) Firat Tip Dergisi 1997;1:1167-1170.

72. Neyzi O, Saner G, Alp H. Relationship between body-weight in infancy and weight in later childhood and adolescense. In Laron Z, ed. Pediatric and Adolescent Endocrinology, volume 1. Basel: Karger, 1976:89-93.

73. Simsek E, Akpinar S, Bahcebası T, Senses DA., Kocabay K. The prevalence of overweight and obese children aged 6-17 years in the West Black Sea region of Turkey. Int J Clin Pract.2008;62:10331038. [Abstract] 